\title{
A case-control study of acute appendicitis and diet in children
}

\author{
M NELSON, J MORRIS, DJP BARKER, AND S SIMMONDS \\ From the MRC Environmental Epidemiology Unit, University of Southampton, Southampton General Hospital, \\ Southampton SO9 $4 X Y$
}

SUMMARY The diets of 53 Southampton children who had had appendicitis were compared with those of two sets of age-sex matched controls using a seven-day weighed food record. One set of controls comprised classmates of the cases; the other was a random sample of all schoolchildren in the city. The cases weighed less and were shorter in height; they had lower intakes of energy, all the main nutrients and water. The differences in weight and water intake were statistically significant. Low water intake was identified as a risk factor independent of other factors. Consumption of dietary fibre from cereals and vegetables in relation to total energy intake and body weight was similar in cases and controls.

The aetiology of acute appendicitis remains unknown. The evidence in support of dietary causes, in particular lack of cereal fibre, ${ }^{12}$ comes largely from international comparisons and is inconclusive. ${ }^{3}$ Case-control studies of diet have given inconsistent results. ${ }^{4-8}$ In only two studies, however, was diet measured by a more precise method than a single interview. Both these studies were based on small numbers of cases and had limited statistical power. We describe a casecontrol comparison of 53 cases and 97 controls in which diet was assessed by a 7-day weighed food diary.

\section{Method}

The study was an extension of an earlier one. ${ }^{4}$ The cases selected were a consecutive series of 55 schoolchildren aged 13 to 15 years who had undergone emergency appendicectomy during 1981-4 and were resident in Southampton. Acute appendicitis had been confirmed by macroscopic and histological examination. Each case was seen between one and 12 months after the operation.

For each case two controls who had not had appendicitis were selected. The first was drawn randomly from the class register of the case; the second was a child randomly selected from the Southampton school registers. The controls were matched for sex and year of age and were seen within one month of the case.

With help from their parents, each case and control weighed and recorded all food and drink consumed during one week. The height and weight of each child were measured.
For two cases neither control completed theo $\frac{0}{\sigma}$ weighed food record and they were therefore excluded. In the analysis the results for the initial 30 cases, previously reported, were combined with those for the subsequent 23 . With this number of cases recording diet over seven days, and with estimated between- and within-person variances in intake derived from the Cambridge Family Food Survey, ${ }^{9}$ this combined study had an estimated $80 \%$ chance of detecting a difference (at the $5 \%$ significance level) of $3.0 \mathrm{~g}$ in average daily fibre intake between the cases and both control groups combined.

Two way analysis of variance was used to test for differences in body size and nutrient intake between cases and their matched controls and between the two control groups.

\section{Results}

The cases comprised 34 boys and 19 girls. Fifty one of their 55 classmates (first controls) and 46 of the 55 randomly selected schoolchildren (second controls) completed the weighed food diaries. The social class distribution of cases and controls was similar. There were no statistically significant differences in body size or nutrient intake between the two control groups. The results for the controls are therefore given for the two groups combined.

The average weight of the cases, $51 \cdot 1 \mathrm{~kg}$, was less than that of the controls, $54.9 \mathrm{~kg}$ (table 1 ). The cases were also shorter, their mean height being $1.61 \mathrm{~m}$ compared with $1.64 \mathrm{~m}$. These differences between cases and controls were statistically significant for weight 
$(p=0.03)$ and on the borderline of significance for height $(p=0.05)$. However, the difference in body mass index (weight/height ${ }^{2}$ ) was small and not significant.

In comparison with the control groups the cases had a lower mean daily intake of energy, protein, fat, carbohydrate, and water (table 2). Carbohydrate is total available carbohydrate from sugar and starches. Water includes all the water contained in foods and beverages. None of the differences was statistically significant at the $5 \%$ level. Logarithmic values of water intake were used in the analysis because their distribution was skewed. The difference in water intake fell just short of statistical significance $(\mathrm{p}=0.06)$.

Table 3 shows the consumption of dietary fibre derived from vegetable and cereal foods. Logarithmic values of total vegetable and potato fibre and cereal fibre consumption from bread were used in the

Table 1 Mean weight, height and body mass index of appendicitis cases and age-sex matched controls.

\begin{tabular}{lccl}
\hline & Cases & Controls & Difference \\
\hline Weight $(\mathrm{kg})$ & $51 \cdot 1$ & 54.9 & $-3.8(-7 \cdot 1,-0.5)$ \\
Height $(\mathrm{m})$ & 1.61 & 1.64 & $-0.03(-0.05,0.00)$ \\
BMI $\left(\mathrm{kg} / \mathrm{m}^{2}\right)$ & 19.6 & 20.4 & $-0.8(-1 \cdot 7,0.08)$ \\
\hline
\end{tabular}

Figures in parentheses are $95 \%$ confidence intervals.

Table 2 Mean daily intakes of energy, nutrients, and water in appendicitis cases and age-sex matched controls.

\begin{tabular}{lccc}
\hline & Cases & Controls & Difference \\
\hline Energy (MJ) & 8.9 & 9.5 & $-0.6(-1 \cdot 2,0 \cdot 03)$ \\
Protein (g) & 65 & 68 & $-2 \cdot 9(-7 \cdot 5,1 \cdot 7)$ \\
Fat (g) & 89 & 96 & $-6 \cdot 6(-14 \cdot 4,1 \cdot 2)$ \\
Carbohydrate (g) & 281 & 298 & $-17(-36,2)$ \\
Water* (g) & 1287 & 1393 & $-108(-209,1)$ \\
\hline
\end{tabular}

Figures in parentheses are $95 \%$ confidence intervals.

*log values used in analysis of variance and in calculation of confidence intervals (geometric means shown in table).

Table 3 Mean intakes of dietary fibre (g/person/day) in appendicitis cases and age-sex matched controls.

\begin{tabular}{llll}
\hline Source of fibre & Cases & Controls & Difference \\
\hline All vegetables* & 8.6 & 8.5 & $0.1(-0.8,1 \cdot 1)$ \\
$\quad$ Potatoes* & 4.05 & 4.00 & $0.05(-0.5,0.7)$ \\
Other than potatoes & 4.65 & 4.68 & $-0.03(-0.9,0.8)$ \\
& & & \\
Cereals & 7.8 & 9.1 & $-1.3(-2.6,0.1)$ \\
$\quad$ Bread* & 2.8 & 3.1 & $-0.4(-0.9,0.3)$ \\
Other cereal foods & 4.5 & 5.1 & $-0.6(-1.6,0.4)$ \\
Total & 19.0 & 20.5 & $-1.5(-3.0,0.0)$ \\
\hline
\end{tabular}

Figures in parentheses are $95 \%$ confidence intervals.

* log values in analysis of variance and in calculation of confidence intervals (geometric means shown in table).
Table 4 Relative risk of appendicitis according to thirds of the distribution of weight and water intake among appendicitis controls.

\begin{tabular}{llll}
\hline & \multicolumn{3}{l}{ Thirds of distribution } \\
\cline { 2 - 4 } & Upper & Middle & Lower \\
\hline Weight & 1 & $2 \cdot 1$ & $2 \cdot 2$ \\
& & $(0 \cdot 8-5 \cdot 1)$ & $(0 \cdot 9-5 \cdot 3)$ \\
Water intake & 1 & $2 \cdot 4$ & $3 \cdot 0$ \\
& & $(0.9-6 \cdot 1)$ & $(1 \cdot 1-8 \cdot 7)$ \\
\hline
\end{tabular}

Figures in parentheses are $95 \%$ confidence intervals

statistical analysis. There was no consistent difference between cases and controls in vegetable fibre. However, using the method of Southgate et al, ${ }^{10}$ cereal fibre consumption from bread and other cereal foods was lower among the cases, $7 \cdot 8 \mathrm{~g}$ compared with $9 \cdot 1 \mathrm{~g}$. This difference was not statistically significant $(p=0.07)$. Individual total fibre intakes ranged from $8.7 \mathrm{~g}$ to $37.7 \mathrm{~g}$ in the cases and from $8.4 \mathrm{~g}$ to $34.3 \mathrm{~g}$ in the controls.

Among the cases and controls there was a positive correlation between the mean daily intakes of fibre and energy $(r=0.65, p<0.001)$. When fibre intake is expressed in relation to energy there was no significant difference between cases and controls in either cereal or vegetable fibre. The mean total fibre intake of cases was $2 \cdot 17 \mathrm{~g} / 1000 \mathrm{~kJ}$ compared with $2 \cdot 18 \mathrm{~g} / 1000 \mathrm{~kJ}$ in the controls.

The variables analysed in tables 1 to 3 were considered together in a logistic regression for matched cases and controls using the observed values. ${ }^{11}$ Only weight and water intake made significant independent contributions to relative risk of appendicitis. Grouping the data in thirds, the relative risk of appendicitis among children in the lower third of weight distribution was twice that of those in the upper third (table 4). The risk in the lower third of water intake distribution was three times that in the upper third.

\section{Discussion}

In this study diet was measured by a seven-day weighed food record, a more precise method than those used in previous case-control studies of appendicitis. The subjects were children, among whom the incidence of appendicitis is highest. The only other study which used a food record rather than dietary recall was restricted to adults and the food portions were unweighed. ${ }^{8}$ Extension of our initial study to 53 cases and 97 controls has given it statistical power to detect small differences in dietary intake.

The mean weights and heights of the cases were less than those of both sets of controls, classmates, and randomly selected Southampton schoolchildren 
318

(table 1). The lower weight of cases could reflect an anorectic response to appendicectomy. However, when the cases were subdivided according to interval between operation and interview, the energy intakes did not increase with increasing interval. Furthermore, the short stature of cases indicates that anorectic response could not be the sole explanation of the case-control differences. Although the social class distributions of cases and controls are similar, the shorter stature of cases could nevertheless reflect socioeconomic differences which independently influence growth and susceptibility to appendicitis.

The water intake of the cases was less than that of both sets of controls (table 2). Multiple logistic regression showed that water had an effect that was independent of other factors, and lower intake was associated with a relative risk of 3.0 (table 4), with $95 \%$ confidence interval $(1 \cdot 1-8 \cdot 7)$. The mechanism underlying this association is unknown. Bowel movement frequency and therefore, by implication, bowel transit time were not related to water intake in the cases and controls.

The mean intake of dietary fibre was lower in the cases (table 3). The difference was dependent on intake of cereal rather than vegetable fibre. However, the cases ate less of all the major nutrients, and there is no difference between cases and controls if fibre intake is expressed in relation to total energy consumption. Multiple logistic regression showed that fibre had no independent effect on appendicitis. In a recent casecontrol study in Washington State, USA, there was no statistically significant difference in total fibre intake of 135 children who had undergone appendicectomy and 212 controls. $^{7}$ There was, however, a significant negative trend in relative risk with increasing intake of certain fibre-containing foods, namely, whole-grain breads and cereals. These findings were based on telephone interviews with parents, enquiring solely about fibre-containing foods. Our study shows that such data cannot be interpreted in the absence of information on other nutrients, water, and body size, and the conclusion that "a liberal intake of wholegrain breads and cereals may decrease the risk of appendicitis during childhood" is not justified.

In Sweden, the diets of 31 adult patients with appendicitis were compared with those of 30 agematched hospital controls using a seven-day food diary. ${ }^{8}$ The mean fibre intake of cases was lower than that of controls after allowance for their lower energy intake. However, in Hong Kong diet histories showed no difference in the dietary fibre intake of 67 cases and controls (Donnan and Ho, unpublished data). Two studies in Britain, using dietary histories, also showed no case-control differences. ${ }^{56}$.

Case-control studies therefore do not provide consistent evidence to support the hypothesis that lack
M Nelson, J Morris, D J P Barker, and S Simmonds

of dietary fibre is a cause of appendicitis. Furthermore, analysis of the time trends of appendicitis in Britain during this century does not support a close association with either cereal or vegetable fibre consumption.

A recent comparison of acute appendicitis rates during 1978-82 and diet in 59 areas of England and Wales revealed no correlation with cereal fibre intake but a negative correlation with consumption of nonpotato vegetables, particularly green vegetables and tomatoes, and a positive correlation with potato consumption. ${ }^{12}$ Green vegetables and tomatoes could protect against appendicitis through mechanisms associated with fibre, whose chemical composition differs in vegetables and cereals. However, this protective effect has not been revealed in a casecontrol study in one town.

We are grateful to the staff in the Paediatric Unit, Pathology and Medical Records Departments, Southampton General Hospital, for their help in the selection of cases; to the head teachers ind Southampton who helped with the selection of controls; and to our colleagues, Paul Winter and Clive Osmond, for computing and statistical advice $\frac{+}{\mathrm{D}}$ Without the cooperation of the children and thei? families, who completed the dietary records, the studø would not have been possible.

\section{References}

${ }^{1}$ Rendle Short A. The causation of appendicitis. Br J Surg 1920; 8: 171-88.

2 Burkitt DP. The aetiology of appendicitis. Br J Surg 1971; 58: 695-99.

3 Barker DJP. Acute appendicitis and dietary fibre: an alternative hypothesis. $\mathrm{Br} \mathrm{Med} J$ 1985; 290: 1125-7.

${ }^{4}$ Nelson M, Barker DJP, Winter PD. Dietary fibre and acute appendicitis: a case-control study. Human Nutrition: Applied Nutrition 1984; 38A: 126-31.

5 Cove-Smith JR, Langman MJS. Appendicitis and dietary fibre. Gut 1975; 16: 409.

${ }^{6}$ Gear JSS. Epidemiological studies of the role of dietary fibre in the aetiology of disease. Thesis; Oxford University 1978.

${ }^{7}$ Brender JD, Weiss NS, Koepsell TD, Marcuse EK. Fiber intake and childhood appendicitis. Am J Publ Hlth 1985; 75: $399-400$.

${ }^{8}$ Arnbjornsson E. Acute appendicitis and dietary fibre. Arch Surg 1983; 118: 868-70.

${ }^{9}$ Nelson M. A dietary survey method for measuring family food purchases and individual nutrient intakes concurrently, and its use in dietary surveillance. PhD thesis, London University 1983.

${ }^{10}$ Southgate DAT, Bailey B, Collinson E, Walker AT. A guide to calculating intakes of dietary fibre. J Hum Nutr 1976: 30: 303-13.

11 Breslow NE, Day NE. Statistical methods in cancer research. Vol 1. The analysis of case-control studies. IARC Scientific Publications no. 32. Lyon: IARC 1980.

12 Barker DJP, Morris J, Nelson M. Vegetable consumption and acute appendicitis in 59 areas in England and Wales. Br Med J 1986; 292: 927-30. 